\title{
Inhibition of NADPH oxidase 4 induces apoptosis in malignant mesothelioma: Role of reactive oxygen species
}

\author{
MOTOYA TANAKA $^{1^{*}}$, YUJI MIURA ${ }^{2 *}$, HIROKI NUMANAMI $^{1}$, SIVASUNDARAM KARNAN $^{3}$, AKINOBU OTA $^{3}$, \\ HIROYUKI KONISHI $^{3}$, YOSHITAKA HOSOKAWA ${ }^{3}$ and MASAYUKI HANYUDA ${ }^{1}$ \\ ${ }^{1}$ Department of Thoracic Surgery, ${ }^{2}$ Pathophysiology, Aichi Medical University School of Nursing, \\ ${ }^{3}$ Department of Biochemistry, Aichi Medical University School of Medicine, Nagakute, Aichi 480-1195, Japan
}

Received May 18, 2015; Accepted July 6, 2015

DOI: $10.3892 /$ or.2015.4155

\begin{abstract}
Malignant pleural mesothelioma (MPM) is an aggressive tumor that is characterized by dysregulated growth and resistance to apoptosis. Reactive oxygen species (ROS)generating NADPH oxidase (Nox) family enzymes have been suggested to be involved in neoplastic proliferation. Both the antioxidant $\mathrm{N}$-acetylcysteine (NAC) and the inhibitor of flavoprotein-dependent oxidase, diphenylene iodonium (DPI), inhibited the cell viability of MPM cells in a dose-dependent manner. To examine whether Nox-mediated ROS generation confers antiapoptotic activity and thus a growth advantage to MPM cells, we analyzed the mRNA expression of Nox family members using quantitative RT-PCR in 7 MPM cell lines and a normal mesothelial cell line. Nox4 mRNA was expressed in all of the examined MPM cell lines, whereas little or no Nox2, Nox3 and Nox5 mRNA expression was detected. In 2 MPM cell lines, Nox4 mRNA expression was significantly higher than that in a normal mesothelial cell line. siRNAs targeting Nox4 suppressed ROS generation and cell viability in the MPM cell lines. In addition, DPI treatment and knockdown of Nox4 attenuated phosphorylation of AKT and ERK. Taken together, our results indicate that Nox4-mediated ROS, at least in part, transmit cell survival signals and their depletion leads to apoptosis, thus highlighting the Nox4-ROS-AKT signaling pathway as a potential therapeutic target for MPM treatment.
\end{abstract}

Correspondence to: Dr Yoshitaka Hosokawa, Department of Biochemistry, Aichi Medical University School of Medicine, 1-1 Karimata Yazako, Nagakute, Aichi 480-1195, Japan

E-mail: hosokawa@aichi-med-u.ac.jp

*Contributed equally

Abbreviations: DCF, dichlorofluorescin; Duox, dual oxidase DCFH-DA, 2',7'-dichlorodihydrofluorescein diacetate; DPI, diphenylene iodonium; MPM, malignant pleural mesothelioma; NAC, $\mathrm{N}$-acetylcysteine; Nox, NADPH oxidase; PBMC, peripheral blood mononuclear cell; ROS, reactive oxygen species

Key words: malignant mesothelioma, NADPH oxidase, reactive oxygen species, apoptosis

\section{Introduction}

Malignant pleural mesothelioma (MPM) are incurable thoracic malignancy, that has poor prognosis because it is frequently diagnosed at an advanced stage $(1,2)$. The worldwide incidence of mesothelioma is expected to increase, particularly in Europe and Japan (3-5). The primary cause of MPM is often linked to asbestos exposure, and the number of patients worldwide is predicted to peak in the next 2 decades $(6,7)$. Investigations for the molecular pathogenesis of MPM has begun (8-12). Recent whole-exome sequencing revealed frequent genetic alterations in $B A P 1, N F 2, C D K N 2 A$ and CUL1 in 22 MPMs (13). The latent period between the first exposure to asbestos and the onset of this disease is $\sim 30$ years, and the first symptom is insidious and may include chest pain and breathlessness. Many clinical trials including surgery, radiotherapy, and chemotherapy were reported, but the prognosis of patients remains poor. Although there was recent progress in clinical treatment with combination chemotherapies, a curative therapy for MPM remains unknown; the median survival ranges between 9 and 17 months after diagnosis (14-17). Combinations of cisplatin and pemetrexed appear to be the best chemotherapy regimen for MPM. Thus, effective clinical approaches such as moleculartargeted therapy are needed to treat MPM.

The recently-discovered epithelial NADPH oxidases (Noxs) mediate critical physiological and pathological processes including cell signaling, inflammation and mitogenesis by generating reactive oxygen species (ROS) (18). The Nox enzyme complex was first described in neutrophils, where it is normally quiescent but generates a large quantity of ROS upon activation during phagocytosis and plays a vital role in nonspecific host defense against ingested pathogens $(19,20)$. Many non-phagocytic cells contain NADPH oxidases (20). There are 7 identified family members in the NADPH family: 5 Noxs and 2 dual oxidases (DUOXs) (20). Noxs and the mitochondria are major sources of cellular ROS (21). Cancer cells produce ROS that act as signaling molecules to promote cell survival $(22,23)$. Nox4-mediated ROS inhibit apoptosis and promote tumor cell growth in pancreatic cancer cells $(24,25)$. However, our understanding of the roles of the Nox family members in the development and growth of human cancer is limited (26-30). 
We hypothesized that intracellular ROS conferred antiapoptotic activity and thus a growth advantage to MPM cells. In this study, we demonstrated that treatment with diphenylene iodonium (DPI), a flavoenzyme inhibitor (31) and knockdown of Nox4 suppressed ROS production in MPM cells, which induced apoptosis, suggesting that Nox4-generated ROS at least in part, transmits cell survival signals and provides a useful clinical approach for MPM treatment.

\section{Materials and methods}

Cell culture andmaterials. Seven MPM cell lines (ACC-MESO-1, ACC-MESO4, Y-MESO-8A, MSTO-211H, NCI-H28, NCI-H290 and NCI-H2052) and a normal mesothelial cell line (Met-5A) were kindly provided by Dr Y. Sekido, Division of Molecular Oncology, Aichi Cancer Center Research Institute. Cells were maintained at $37^{\circ} \mathrm{C}$ under $5 \% \mathrm{CO}_{2}$ air atmosphere in DMEM culture medium (Sigma, St. Louis, MO, USA) supplemented with $10 \%$ heat-inactivated FBS, 2 mM L-glutamine, $200 \mathrm{U} / \mathrm{ml}$ penicillin and $100 \mu \mathrm{g} / \mathrm{ml}$ streptomycin. Heparinized peripheral blood was collected from normal individuals after informed consent was obtained, and PBMCs were separated using density-gradient centrifugation.

Analysis and quantification of Nox4 mRNA levels by RT-PCR and real-time $P C R$. Reverse transcription (RT) was conducted as follows: $8 \mu \mathrm{l}$ water containing $1 \mu \mathrm{g}$ total RNA was added to $50 \mathrm{ng}$ random primers (Life Technologies) and incubated at $65^{\circ} \mathrm{C}$ for $5 \mathrm{~min}$. cDNA was prepared with SuperScript III First-Strand Synthesis Supermix (Invitrogen, Carsbad, CA, USA) according to the manufacturer's protocol.

Real-time PCR was performed using SYBR Premix Ex Taq II (Takara Bio, Otsu, Shiga, Japan), and PCR amplifications were performed in an ABI PRISM 7500 Sequence Detection System (Applied Biosystems, Foster City, CA, USA). Briefly, a solution of SYBR Premix Ex Taq II (10 $\mu$; : Takara Bio) containing sense and antisense primers (10 $\mu \mathrm{M}$ each) was prepared and $2 \mu \mathrm{l}$ cDNA was added to a final volume of $20 \mu \mathrm{l}$. Conditions for PCR included $42^{\circ} \mathrm{C}$ for $5 \mathrm{~min}, 95^{\circ} \mathrm{C}$ for $10 \mathrm{sec}$, and 40 cycles of $95^{\circ} \mathrm{C}$ for $5 \mathrm{sec}$ and $60^{\circ} \mathrm{C}$ for $34 \mathrm{sec}$. Data were analyzed with Sequencer Detector version 1.6 software (ABI-PE). The threshold cycle (CT) during the exponential phase of amplification was determined by real-time monitoring of fluorescent emission by nuclease activity of Taq polymerase. $\beta$-actin was used as an internal control. Relative transcripts were determined by the following formula: $1 / 2^{\text {(CTtarget - CTcontrol) }}$ (32). Specific primers for Noxs 1-5 and $\beta$-actin were synthesized (Star Oligo Rikaken, Nagoya, Japan). PCR primer pairs were as follows: Noxl, sense 5'-AGCGTC TGCTCTCTGCTTGAA-3' and antisense 5'-GGCTGCAAA ATGAGCAGGT-3'; Nox2, sense 5'-TGCCTTTGAGTGGTTT GCAGAT-3' and antisense 5'-ATTGGCCTGAGACTCAT CCCA-3'; Nox3, sense 5'-GAACCCTCGGCTTGGAAAT-3' and antisense 5'-TGGCTTACCACCTTGGTAATGA-3'; Nox4, sense 5'-CCCTCACAATGTGTCCAACTGA-3' and antisense 5'-GGCAGAATTTCGGAGTCTTGAC-3'; Nox5, sense 5'-AAGAGTCAAAGGTCGTCCAAGG-3' and antisense 5'-GCTTTCTTTTCTGGTGCCTGT-3'; $\beta$-actin, sense 5'-GAT GACCCAGATCATGTTTGAGACC-3' and antisense 5'-CGG TGAGGATCTTCATGAGGTAGT-3'.
Cell viability assay. The viability of the cells transfected with Nox4 siRNAs or treated with NAC, DPI, or specific inhibitors for protein kinases was determined using the MTT assay. MPM cells $\left(1 \times 10^{3}\right)$ were incubated with each reagent at each concentration in triplicate in 96-well culture plates at $37^{\circ} \mathrm{C}$ in humidified air with $5 \% \mathrm{CO}_{2}$. Three wells contained MPM cells in drug-free medium to determine the control cell survival and the percentage of cells after culture. Three wells contained medium only to blank the spectrophotometer. After 2 days, $10 \mu \mathrm{l}(5 \mathrm{mg} / \mathrm{ml})$ MTT salt was added for $6 \mathrm{~h}$. Formazan production was quantitated using a spectrophotometer at $562 \mathrm{~nm}$. The optical density (OD) is linearly related to the cell number. Cell survival (CS) was calculated at each drug concentration by the equation $\mathrm{CS}=(\mathrm{OD}$ treated well $/$ mean OD control wells) x $100 \%$.

Flow cytometric analysis of apoptosis. To analyze apoptosis, the externalization of phosphatidylserine was measured by flow cytometric staining with FITC-conjugated Annexin V (BD Pharmingen). Cells in 6 -well plates $\left(2 \times 10^{5}\right.$ cells per well) were treated for $48 \mathrm{~h}$, washed, resuspended in $100 \mu \mathrm{l}$ Annexinbinding buffer, and stained with $5 \mu$ l Annexin V-FITC and propidium iodide for $20 \mathrm{~min}$. Flow cytometric analysis was performed using FACSCalibur (BD Biosciences) and Cell Quest Pro Version 4.0.2 (BD Biosciences) software. Cells that were positively stained with Annexin V were counted as apoptotic populations.

Measurement of intracellular ROS production. Cells $\left(2 \times 10^{5}\right.$ per well) were seeded in 6-well plates and treated with $10 \mu \mathrm{M}$ DPI for $48 \mathrm{~h}$ or transfected Nox4 siRNAs. Then, cells were incubated with $2.5 \mu \mathrm{M}$ of 2',7'-dichlorodihydrofluorescein diacetate (DCFH-DA; Molecular Probes, Eugene, OR, USA) for $30 \mathrm{~min}$ at $37^{\circ} \mathrm{C}$ in the dark, washed with Hank's buffer, and fixed in $1 \%$ paraformaldehyde. The fluorescence intensity was measured using FACS, with the excitation source at $488 \mathrm{~nm}$ and an emission wavelength of $580 \mathrm{~nm}$. An analysis was performed with the software program BD FACStationt System Data Management System (Becton-Dickinson). Background fluorescence from the blank was subtracted from each reading.

Transfection and immunoblotting. Cells were transfected with Nox4 siRNAs or scramble siRNAs utilizing Lipofectamine 2000 (Invitrogen) according to the manufacturer's protocol. siRNAs were designed from the human Nox 4 cDNA sequences as follows (Integrated DNA Technologies, Coralville, IA, USA): 5'-GCUGAAGUAUCAAACUAUUUAGAT-3' and 5'-AUCUA AAUUAGUUUGAUACUUCAGCAG-3' for Nox4RNAi-1, and 5'-GAAUUACAGUGAAGACUUUGUUGAA-3' and 5'-UUC AACAAAGUCUUCACUGUAAUUCAC-3' for Nox4RNAi-2. Universal scrambled siRNA sequences, which have no significant homology to mouse, rat, or human genome databases, were used as controls (Invitrogen).

For western blot analysis, equal amounts of reduced proteins $(20 \mu \mathrm{g})$ were loaded on $10 \%$ Bis-Tris-buffered polyacrylamide gels. After gel electrophoresis, proteins were transferred to PVDF membranes (Invitrogen) by electroblotting. The membranes were preincubated for $1 \mathrm{~h}$ in $5 \%$ low-fat dried milk in TBS and $0.1 \%$ Tween-20 (TBS-T) to block non-specific binding sites. After washing with TBS-T, 

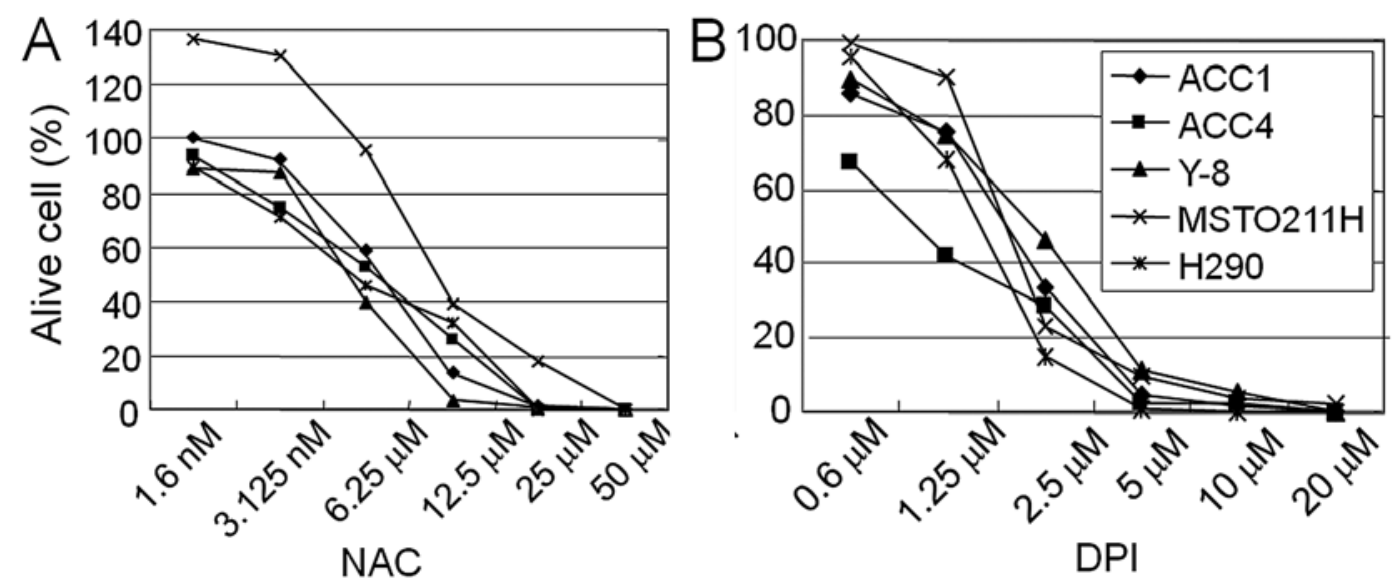

Figure 1. Effects of NAC and DPI on the viability of MPM cells. MPM cells $\left(1 \times 10^{3}\right)$ were treated with NAC (A) or DPI (B) at the indicated concentrations for $48 \mathrm{~h}$. The viability of the cells was determined by an MTT assay. The $\mathrm{IC}_{50}$ values of these drugs were extrapolated from the respective dose-response curves. The data are means $(n=3)$.

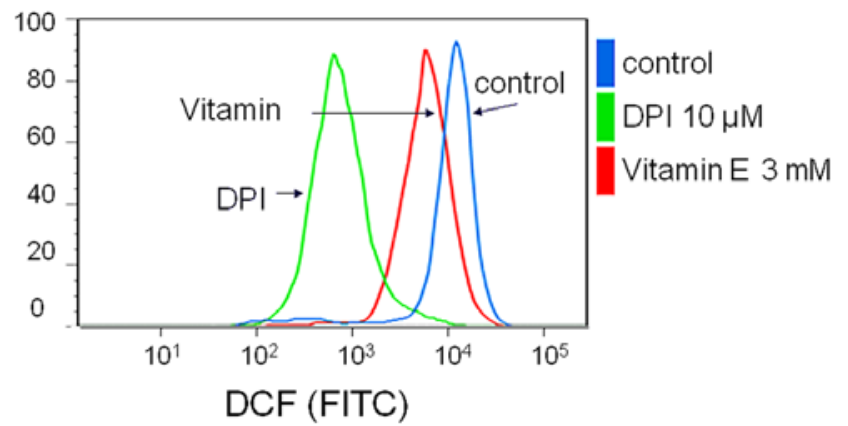

Figure 2. Inhibition of ROS production by DPI or vitamin E. ACC4 cells $\left(1 \times 10^{5}\right)$ were cultured in a 24 -well plate for $48 \mathrm{~h}$. Cells were treated with or without DPI $(10 \mu \mathrm{M})$ or vitamin $\mathrm{E}(3 \mathrm{mM})$. The cells were labeled with DCFH-DA and alterations in the intracellular ROS level were measured by FACS analysis. A typical profile of FACS analysis is shown. The horizontal axis indicates the fluorescence intensity with the excitation source at $488 \mathrm{~nm}$ and an emission wavelength of $580 \mathrm{~nm}$.

membranes were incubated overnight with a 1:1,000 dilution of primary antibody in TBS-T containing 5\% BSA at $4^{\circ} \mathrm{C}$ (Cell Signaling Technology), and probed with horseradish peroxidase-conjugated secondary antibody (1:2,000 dilution) for $1 \mathrm{~h}$ at room temperature. The bound antibodies were visualized with the ECL reaction (GE Healthcare).

Statistical analysis. Data were analyzed by the Welch t-test, Fisher's exact-test, or ANOVA using Statview software (SAS, Cary, NC, USA), and P-values at $<0.05$ were considered to be statistically significant.

\section{Results}

Inhibition of cell growth, suppression of ROS generation, and induction of apoptosis by antioxidants. The flavoenzyme inhibitor, DPI inhibits membrane-bound, flavoproteincontaining Noxs. We examined whether the antioxidant NAC and the flavoenzyme inhibitor DPI, affected the cell viability of mesothelioma cell lines. Five MPM cell lines (ACC1-MESO, ACC4-MESO, Y8-MESO, MSTO-211H and H290) were treated with various concentrations of NAC or DPI for $48 \mathrm{~h}$. Both NAC and DPI treatments inhibited the cell viability in a dose-dependent manner (Fig. 1). The $\mathrm{IC}_{50}$ values for DPI were as follows: $2.1 \mu \mathrm{M}$ (ACC1-MESO), $0.8 \mu \mathrm{M}$ (ACC4-MESO), $2.5 \mu \mathrm{M}$ (Y8-MESO), $2.2 \mu \mathrm{M}$ (MSTO-211H) and $2.2 \mu \mathrm{M}$ (H290).

To verify that antioxidants affect ROS generation, we evaluated ROS production using flow cytometry. With vitamin $\mathrm{E}$ and DPI treatment, DCF fluorescence intensity, $2.1 \times 10^{4}$ in untreated cells was reduced to $0.7 \times 10^{4}$ and $0.1 \times 10^{4}$, respectively (Fig. 2). Thus, MPM cells regularly generated ROS, and both vitamin E and DPI treatment suppressed ROS generation.

We further examined the effect of DPI on the induction of apoptosis of MPM cells using Annexin V assay. DPI treatment significantly induced apoptosis (27 and 26\%) in ACC1 and MSTO-221H cells, respectively (Fig. 3). Our results strongly suggest that depletion of ROS leads to the apoptosis of MPM cells.

Expression and quantification of Nox 1-5 mRNAs in MPM cell lines. The Nox family members produce ROS that are though to be pivotal for cell proliferative signaling. To examine the role of the Nox family in proliferation of MPM cells, we analyzed the mRNA expression of Nox family members in 7 MPM cell lines and a non-malignant mesothelial cell line (Met-5A) (Fig. 4). Nox4 mRNA was expressed in all of the examined MPM cell lines, whereas little or no Nox2, Nox3 and Nox 5 mRNAs were detected (Fig. 4). In the ACC-MESO4 cell line, Noxl mRNA expression was readily detected.

Subsequently, the expression levels of Noxs 1-5 relative to $\beta$-actin were measured by quantitative real-time RT-PCR (Fig. 5). Expression was arbitrarily graded as low (Nox copy number $/ \beta$-actin copy number $\left.<500 \times 10^{-8}\right)$, intermediate (ratio $>500$ but $<2,000 \times 10^{-8}$ ) or high (ratio $>2,000 \times 10^{-8}$ ). Nox genes with expression ratios $>500 \times 10^{-8}$ were routinely visible by RT-PCR analysis using $\geq 40 \mu \mathrm{g}$ total RNA. High- or intermediate-level Nox4 mRNA expression was observed in all examined MPM cell lines. Especially, 2 ACC-MESO4 and MSTO-211H cell lines expressed Nox4 mRNA at a high level. For comparison, we examined expression of the Nox family in 

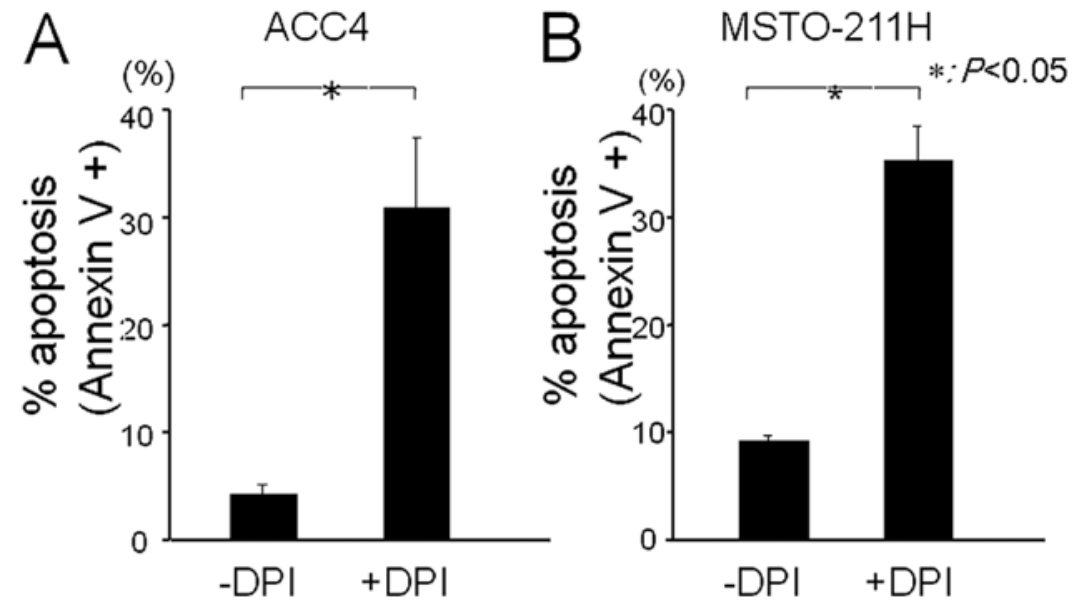

Figure 3. Induction of apoptosis in MPM cells by DPI. (A) ACC4 cells and (B) MSTO-211H cells ( $\left.1 \times 10^{5} / \mathrm{ml}\right)$ were inoculated and, cultured in 24-well plates, and treated with $10 \mu \mathrm{M}$ DPI for $48 \mathrm{~h}$. The numbers of apoptotic cells were determined by Annexin V staining. Error bars represent the SD for 3 samples. An asterisk $(*)$ indicates a significant difference with a P-value $<0.05(n=3)$.

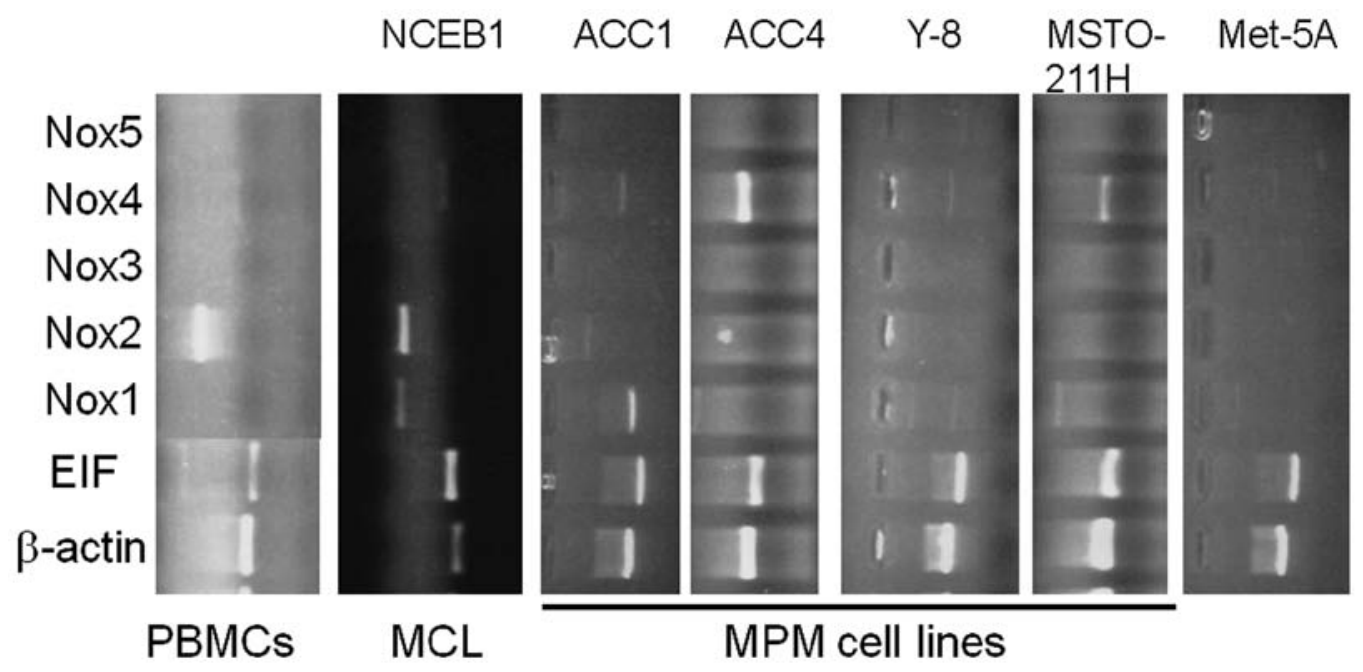

Figure 4. mRNA expression of Nox family members in human MPM cell lines. Total RNAs were extracted from MPM cells, and the mRNA expressions of Nox family members were analyzed by RT-PCR with $\beta$-actin and EF1- $\alpha$ expression as internal controls.

several lymphoma/leukemia cell lines; mantle lymphoma cells and Jurkat leukemia cells expressed low levels of Nox2 mRNA (Fig. 5). High levels of Nox2 were detected in human PBMCs (Fig. 5) and the Jurkat cell line (data not shown).

Nox4 mediates ROS production in MPM cells. We utilized an RNA interference approach to verify whether Nox4 mediates ROS production in MPM cells. The expression of endogenous Nox4 mRNAs in ACC-MESO4 and MSTO$211 \mathrm{H}$ cells was significantly suppressed upon transfection of Nox4 siRNAs, (Fig. 6A). Intracellular ROS production was evaluated by flow cytometry. The transfection of Nox4 siRNAs significantly suppressed ROS levels compared to controls (Fig. 6B), indicating that Nox4, at least in part, is responsible for intracellular ROS generation. However, the ROS generation was not completely inhibited by transfection of Nox4 siRNAs, suggesting the possibility that other Nox members and mitochondria sources may also contribute to ROS generation.

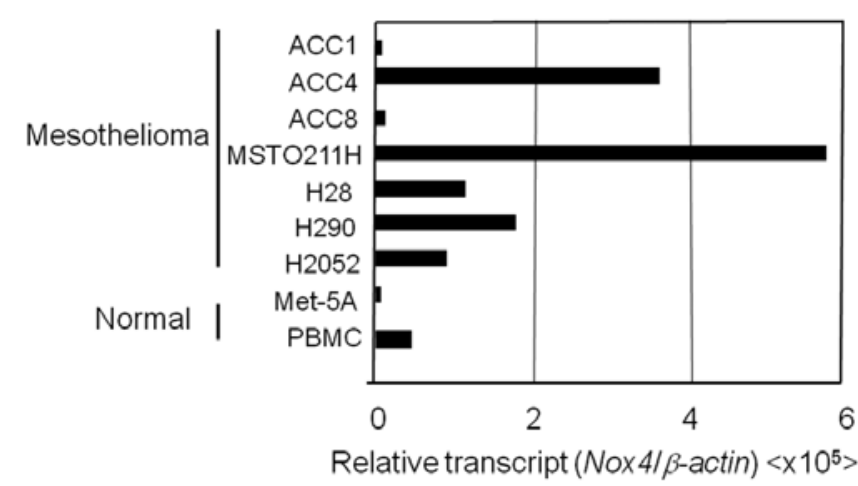

Figure 5. Quantitative analysis of Nox4 mRNA expression in MPM cells. Realtime PCR was performed using SYBR green assay in an ABI PRISM 7700 Sequence Detection System. The threshold cycle (CT) during the exponential phase of amplification was determined by real-time monitoring of fluorescent emission by nuclease activity of Taq polymerase. $\beta$-actin was used as an internal control for mRNA expression. Real-time PCR efficiency of target (Nox1-5) and reference ( $\beta$-actin) was approximately equal over a concentration range of 0.1-200 ng cDNA. Relative transcripts were determined by the formula: $1 / 2^{\text {(CTarget - CTcontrol). }}$ 

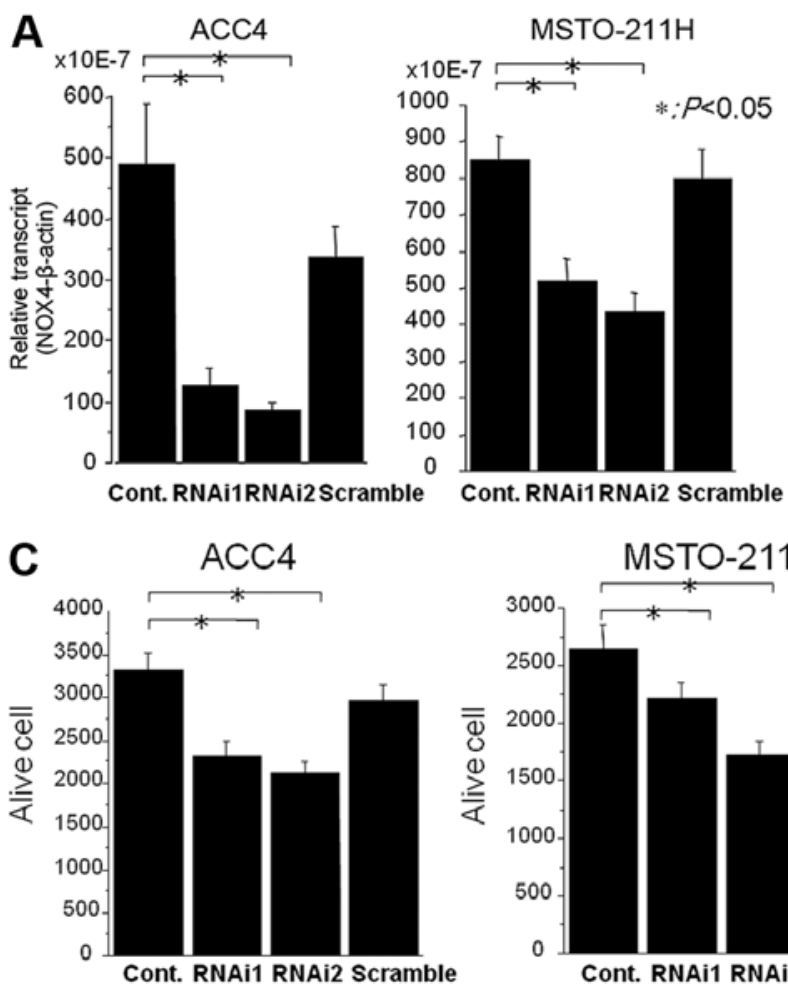

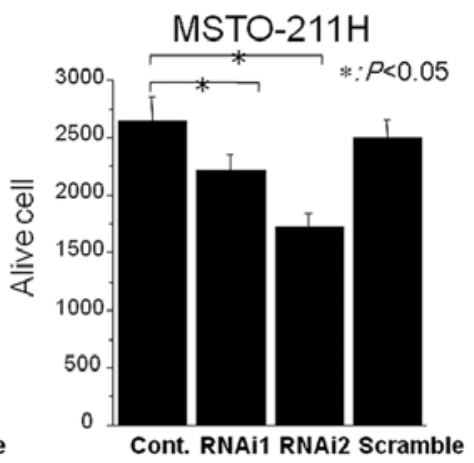

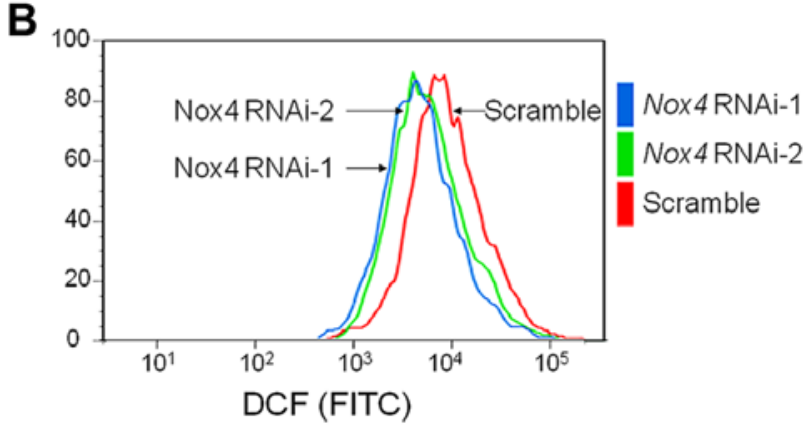

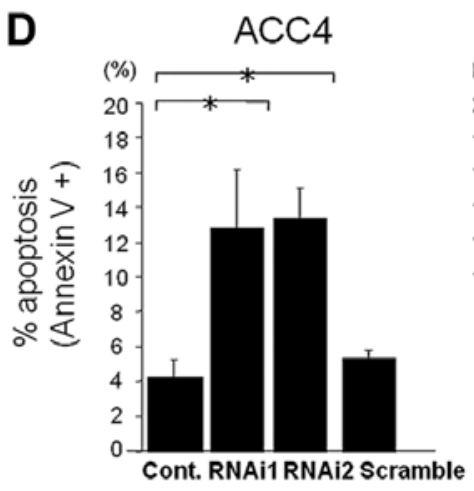

MSTO-211H

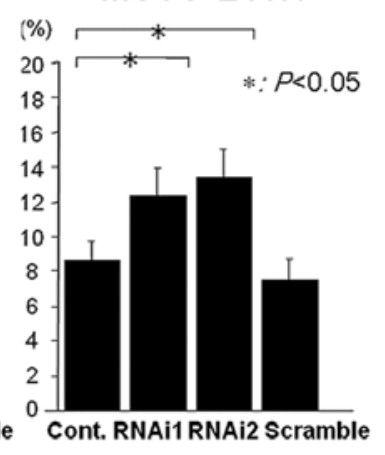

Figure 6. Inhibition of ROS production and induction of apoptosis by Nox4 siRNAs. ACC4 and MSTO-211H cells $\left(5 \times 10^{6}\right)$ were transfected with Nox4 siRNA-1, Nox4 siRNA-2 and scrambled siRNA. (A) The expression levels of endogenous Nox4 mRNAs, relative to $\beta$-actin mRNA as a control, were examined by quantitative RT-PCR at $48 \mathrm{~h}$ after transfection. (B) ACC4 cells were seeded in 6 -well plates $\left(2 \times 10^{5}\right.$ cells/well) and, incubated overnight, and transfected with Nox4 siRNA-1, Nox4 siRNA-2 and scrambled siRNAi. After 48 h, the cells were labeled with DCFH-DA, and alterations in the intracellular ROS level were measured by FACS analysis. A typical profile of FACS analysis is shown, and DCF fluorescence was normalized to that in cells transfected only with scrambled siRNAs. The viability and induction of apoptosis in ACC4 and MSTO-211H cells $\left(2 \times 10^{5}\right)$ transfected with Nox4 siRNA were assayed for MTT (C) or apoptosis (D) assay as per protocol. Error bars represent the SD for 3 samples. An asterisk (*) indicates a significant difference with a $\mathrm{P}$-value $<0.05$ ( $\mathrm{n}=3$ ).

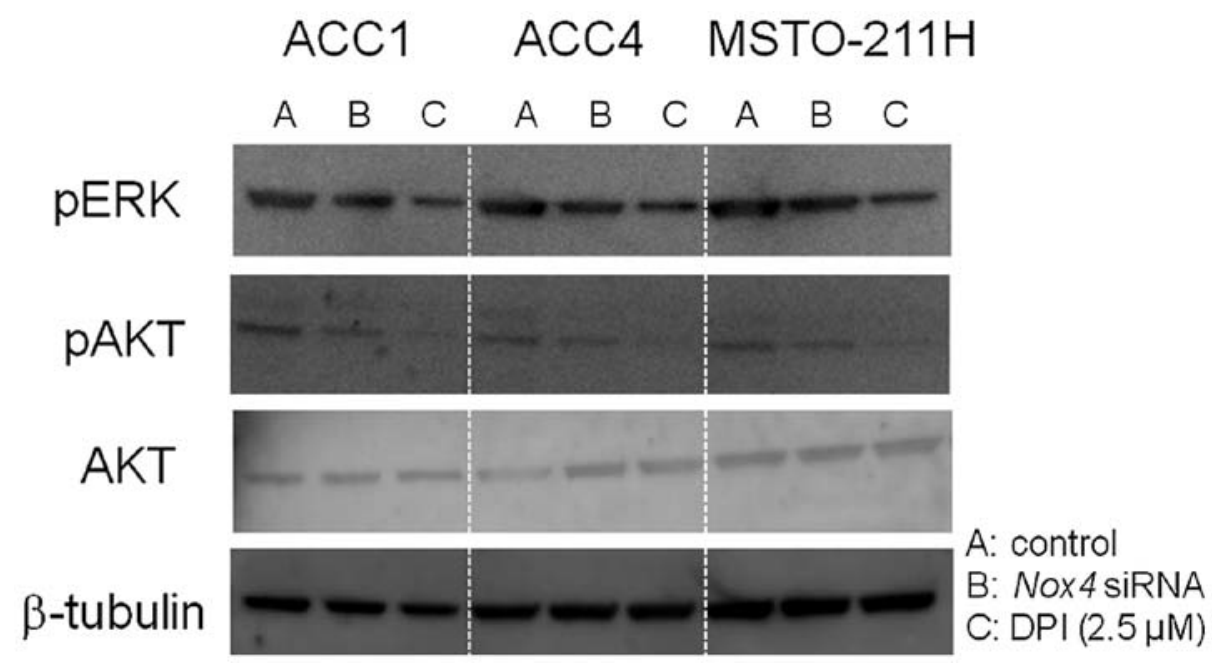

Figure 7. Attenuated phosphorylation levels of AKT and ERK by Nox4 siRNAs or DPI. ACC1, ACC4, and MSTO-211H cells were transfected with Nox4 siRNA-1 or treated with DPI $(2.5 \mu \mathrm{M})$ for $24 \mathrm{~h}$, and the cell lysates were prepared. Twenty micrograms of proteins was subjected to western blot analysis to detect the phosphorylation levels of AKT and ERK. $\beta$-tubulin was used as an internal control for protein expression.

Suppression of ROS generation by Nox4 siRNAs induces apoptosis. To explore whether Nox4-generated ROS regulate cell survival, we examined the effect of Nox4 siRNAs on cell viability and apoptosis. The knockdown of Nox4 significantly reduced the cell viability of ACC-MESO 4 and MSTO-211H cells by $30 \%$ (Fig. 6C). To verify whether the inhibitory effect of Nox4 siRNAs is associated with apoptosis, an Annexin V assay was performed. The transfection of Nox4 siRNAs induced apoptosis by $13 \%$ in MPM cells (Fig. 6D). Thus, Nox4 siRNAs suppressed ROS production, and the depletion of ROS by Nox4 siRNAs and DPI treatment induced apoptosis in MPM cells. 
The role of protein kinases in cell survival signaling in MPM cells. Both PI3K/AKT and MEK/ERK1/2 signaling cascades have important roles in cell proliferation, but they also mediate apoptosis (33). Western blot analysis showed that ACC1, ACC4, and MSTO-211H cell lines expressed phospho-AKT and phospho-ERK (Fig. 7). Nox4 siRNAs transfection and DPI treatment attenuated the phosphorylation of AKT and ERK. Given that transfection of Nox4 siRNAs and DPI treatment induced apoptosis in MPM cells, the inactivation of PI3K/AKT and MEK/ERK1/2 signaling cascades likely plays an important role in the induction of apoptosis.

\section{Discussion}

It is well established that the development of MPM is associated with asbestos exposure $(34,35)$. Chronic inflammation accelerates the development and progression of malignant mesothelioma, possibly because of cytokine release and ROS generation. The inflammation that infiltrate into tissue areas containing asbestos deposits consists largely of phagocytic macrophages that internalize asbestos and release numerous cytokines and mutagenic ROS.

In this study, we first examined the role of ROS in cell proliferation. Although ROS are thought to cause stressinduced apoptosis, ROS often provide cancer cells with a survival advantage. In fact, we showed that suppression of ROS levels by NAC and DPI treatment reduced the viability of MPM cells. Similar results were observed in other cancer cells including pancreatic cells. Second, we examined whether the Nox4-mediated generation of intracellular ROS conferred antiapoptotic activity and thus a growth advantage to MPM cells. To this end, we analyzed the expression levels of Nox genes in 7 MPM cell lines, and a normal mesothelial cell line. RT-PCR analysis revealed that Nox4 mRNA was expressed in all MPM cell lines, whereas little or no Nox2, Nox3 and Nox5 mRNAs were detected. Quantitative real-time RT-PCR also revealed that a high or intermediate level of Nox4 mRNA expression was observed in all MPM cell lines; high-level expression was detected in ACC-MESO4 and MSTO-211H cells compared to the normal mesothelial cell line Met-5A $(\mathrm{P}<0.01)$.

The siRNAs targeting Nox4 in 2 MPM cell lines reduced intracellular ROS generation by $50 \%$, and cell viability by $30 \%$. The depletion of ROS by DPI treatment or knockdown of Nox4 induced apoptosis. Collectively, our findings suggest that ROS generated by Nox4, at least in part, transmit cell survival signals and their depletion leads to apoptosis. High-level NoxI mRNA expression was observed in colorectal cancer cell lines. Growth inhibition profiling of DPI revealed a modest positive correlation with Noxl levels (31). Exposure of HT-29 colon cancer cells, which expresses Noxl, to DPI had inhibitory effects on the steady-state ROS levels, and decreased STAT, ERK1/2, and AKT signaling activity (31). Nox4 overexpression is also reported in primary breast, ovarian, prostate, melanoma, and glioblastoma cancer cell lines (36-38). Nox4 expression was intermediate to high in 2 of the 4 tested ovarian cancer cell lines. Notably, in A2780/DDP cells, high level acquired resistance to cisplatin was associated with a marked decrease in the expression level of Nox4. Recently, Nox4 was shown to be an oncoprotein localized to mitochondria (39). Together with these studies, our study suggests that Nox4 may act as an oncogene, and Nox4-related signaling molecules may be good candidates for molecular-targeted therapy for MPM. Given a possible role of Nox4 in tumorigenesis, it will be of particular interest to investigate the correlation of Nox4 expression in primary mesotheliomas and prognosis in the patients.

AKT (protein kinase B) is a regulator of cell survival in response to a growth factor. AKT is activated through its phosphorylation, and it inhibits apoptosis-inducing proteins, thereby promoting cell survival. The ERK pathway is mostly activated by growth factors and mediates cell proliferation, but it also mediates apoptosis by stress stimuli (33). To examine the role of AKT and ERK in the apoptosis of MPM cells, we evaluated the phosphorylation state of AKT and ERK. Both DPI treatment and knockdown of Nox4 attenuated their phosphorylation levels, suggesting that AKT and ERK play a role in cell survival signals in MPM cells. Consistent with our results, the PI3K-AKT pathway was reported to be activated in human malignant mesothelioma (40). In addition, both selective inhibitors for PI3K/AKT and MEK/ERK1/2 were effective in downregulating the expression of prometastasis phenotypes of MPM cells (41).

In conclusion, we demonstrated that Nox4-mediated ROS generation, at least in part, transmits cell survival signals, and ROS depletion by the knockdown of Nox4 and DPI treatment leads to apoptosis in a subset of MPM cells. Our study raises the possibility of the Nox4-ROS-AKT signaling pathway as a novel therapeutic target for MPM. Antioxidant treatment targeted to this signaling pathway has the potential to enhance the therapeutic index of cisplatin-based therapy. Further studies are warranted to contribute to the knowledge required to ultimately develop targeted therapies for MPM.

\section{Acknowledgements}

This study was supported by grant AI 52213 from the Aichi Cancer Center to Y.M. and a grant of Strategic Research Foundation Grant-Aided Project for Private Universities from the Ministry of Education, Culture, Sports, Science and Technology, Japan (MEXT) to Y.H. The authors thank Dr Yoshitaka Sekido (Division of Molecular Oncology Aichi Cancer Center Research Institute) for providing MPM cell lines.

\section{References}

1. Robinson BW and Lake RA: Advances in malignant mesothelioma. N Engl J Med 353: 1591-1603, 2005.

2. Campbell NP and Kindler HL: Update on malignant pleural mesothelioma. Semin Respir Crit Care Med 32: 102-110, 2011.

3. Peto J, Decarli A, La Vecchia C, Levi F and Negri E: The European mesothelioma epidemic. Br J Cancer 79: 666-672, 1999.

4. Murayama T: Epidemic of asbestos related diseases. In: Proceedings of the Global Asbestos Congress (Tokyo): 17, 2004.

5. Stewart DJ, Martin-Ucar A, Pilling JE, Edwards JG, O'Byrne KJ and Waller DA: The effect of extent of local resection on patterns of disease progression in malignant pleural mesothelioma. Ann Thorac Surg 78: 245-252, 2004.

6. Takahashi K: Emerging health effects of asbestos in Asia. In: Proceedings of the Global Asbestos Congress (Tokyo): 2 , 2004.

7. Murayama T, Takahashi K, Natori Y and Kurumatani N: Estimation of future mortality from pleural malignant mesothelioma in Japan based on an age-cohort model. Am J Ind Med 49: 1-7, 2006 
8. Rascoe PA, Jupiter D, Cao X, Littlejohn JE and Smythe WR: Molecular pathogenesis of malignant mesothelioma. Expert Rev Mol Med 14: e12, 2012. doi: 10.1017/erm.2012.

9. Murakami H, Mizuno T, Taniguchi T, Fujii M, Ishiguro F, Fukui T, Akatsuka S, Horio Y, Hida T, Kondo Y, et al: LATS2 is a tumor suppressor gene of malignant mesothelioma. Cancer Res 71: 873-883, 2011.

10. Fujii M, Toyoda T, Nakanishi H, Yatabe Y, Sato A, Matsudaira Y, Ito $\mathrm{H}$, Murakami $\mathrm{H}$, Kondo $\mathrm{Y}$, Kondo $\mathrm{E}$, et al: TGF- $\beta$ synergizes with defects in the Hippo pathway to stimulate human malignant mesothelioma growth. J Exp Med 209: 479-494, 2012.

11. Shi Y, Moura U, Opitz I, Soltermann A, Rehrauer H, Thies S, Weder W, Stahel RA and Felley-Bosco E: Role of hedgehog signaling in malignant pleural mesothelioma. Clin Cancer Res 18: 4646-4656, 2012.

12. Testa JR, Cheung M, Pei J, Below JE, Tan Y, Sementino E, Cox NJ, Dogan AU, Pass HI, Trusa S, et al: Germline BAP1 mutations predispose to malignant mesothelioma. Nat Genet 43 : 1022-1025, 2011.

13. Guo G, Chmielecki J, Goparaju C, Heguy A, Dolgalev I, Carbone M, Seepo S, Meyerson M and Pass HI: Whole-exome sequencing reveals frequent genetic alterations in BAP1, NF2, CDKN2A, and CUL1 in malignant pleural mesothelioma. Cancer Res 75: 264-269, 2015.

14. Vogelzang NJ, Rusthoven JJ, Symanowski J, Denham C, Kaukel E, Ruffie P, Gatzemeier U, Boyer M, Emri S, Manegold C, et al: Phase III study of pemetrexed in combination with cisplatin versus cisplatin alone in patients with malignant pleural mesothelioma. J Clin Oncol 21: 2636-2644, 2003.

15. Tsao AS, Wistuba I, Roth JA and Kindler HL: Malignant pleural mesothelioma. J Clin Oncol 27: 2081-2090, 2009.

16. Stahel RA and Weder W: Improving the outcome in malignant pleural mesothelioma: Nonaggressive or aggressive approach? Curr Opin Oncol 21: 124-130, 2009.

17. Kindler HL, Karrison TG, Gandara DR, Lu C, Krug LM, Stevenson JP, Jänne PA, Quinn DI, Koczywas MN, Brahmer JR, et al: Multicenter, double-blind, placebo-controlled, randomized phase II trial of gemcitabine/cisplatin plus bevacizumab or placebo in patients with malignant mesothelioma. J Clin Oncol 30: 2509-2515, 2012.

18. Brar SS, Kennedy TP, Sturrock AB, Huecksteadt TP, Quinn MT, Whorton AR and Hoidal JR: An NAD $(\mathrm{P}) \mathrm{H}$ oxidase regulates growth and transcription in melanoma cells. Am J Physiol Cell Physiol 282: C1212-C1224, 2002.

19. Lambeth JD: NOX enzymes and the biology of reactive oxygen. Nat Rev Immunol 4: 181-189, 2004

20. Dworakowski R, Anilkumar N, Zhang M and Shah AM: Redox signalling involving NADPH oxidase-derived reactive oxygen species. Biochem Soc Trans 34: 960-964, 2006.

21. Chen K, Craige SE and Keaney JF Jr: Downstream targets and intracellular compartmentalization in Nox signaling. Antioxid Redox Signal 11: 2467-2480, 2009.

22. Storz P: Reactive oxygen species in tumor progression. Front Biosci 10: 1881-1896, 2005

23. Szatrowski TP and Nathan CF: Production of large amounts of hydrogen peroxide by human tumor cells. Cancer Res 51: 794-798, 1991 .

24. Mochizuki T, Furuta S, Mitsushita J, Shang WH, Ito M, Yokoo Y, Yamaura M, Ishizone S, Nakayama J, Konagai A, et al: Inhibition of NADPH oxidase 4 activates apoptosis via the AKT/apoptosis signal-regulating kinase 1 pathway in pancreatic cancer PANC-1 cells. Oncogene 25: 3699-3707, 2006.

25. Vaquero EC, Edderkaoui M, Pandol SJ, Gukovsky I and Gukovskaya AS: Reactive oxygen species produced by NAD $(\mathrm{P}) \mathrm{H}$ oxidase inhibit apoptosis in pancreatic cancer cells. J Biol Chem 279: 34643-34654, 2004
26. Cheng G, Cao Z, Xu X, van Meir EG and Lambeth JD: Homologs of gp91phox: Cloning and tissue expression of Nox3, Nox4, and Nox5. Gene 269: 131-140, 2001.

27. Donkó A, Péterfi Z, Sum A, Leto T and Geiszt M: Dual oxidases. Philos Trans R Soc Lond B Biol Sci 360: 2301-2308, 2005.

28. Geiszt M, Witta J, Baffi J, Lekstrom K and Leto TL: Dual oxidases represent novel hydrogen peroxide sources supporting mucosal surface host defense. FASEB J 17: 1502-1504, 2003.

29. Juhasz A, Ge Y, Markel S, Chiu A, Matsumoto L, van Balgooy J, Roy K and Doroshow JH: Expression of NADPH oxidase homologues and accessory genes in human cancer cell lines, tumours and adjacent normal tissues. Free Radic Res 43: 523-532, 2009.

30. Wu Y, Antony S, Juhasz A, Lu J, Ge Y, Jiang G, Roy K and Doroshow JH: Up-regulation and sustained activation of Stat1 are essential for interferon-gamma (IFN-gamma)-induced dual oxidase 2 (Duox2) and dual oxidase A2 (DuoxA2) expression in human pancreatic cancer cell lines. J Biol Chem 286: 12245-12256, 2011.

31. Doroshow JH, Juhasz A, Ge Y, Holbeck S, Lu J, Antony S, Wu Y, Jiang $\mathrm{G}$ and Roy K: Antiproliferative mechanisms of action of the flavin dehydrogenase inhibitors diphenylene iodonium and di-2-thienyliodonium based on molecular profiling of the NCI-60 human tumor cell panel. Biochem Pharmacol 83: 1195-1207, 2012.

32. Miura Y, Thoburn CJ, Bright EC, Phelps ML, Shin T, Matsui EC, Matsui WH, Arai S, Fuchs EJ, Vogelsang GB, et al: Association of Foxp3 regulatory gene expression with graft-versus-host disease. Blood 104: 2187-2193, 2004.

33. Lee YJ, Cho HN, Soh JW, Jhon GJ, Cho CK, Chung HY, Bae S, Lee SJ and Lee YS: Oxidative stress-induced apoptosis is mediated by ERK1/2 phosphorylation. Exp Cell Res 291: 251-266, 2003.

34. Carbone M and Yang H: Molecular pathways: Targeting mechanisms of asbestos and erionite carcinogenesis in mesothelioma. Clin Cancer Res 18: 598-604, 2012.

35. Carbone M, Ly BH, Dodson RF, Pagano I, Morris PT, Dogan UA, Gazdar AF, Pass HI and Yang H: Malignant mesothelioma: Facts, myths, and hypotheses. J Cell Physiol 227: 44-58, 2012.

36. Ushio-Fukai $M$ and Nakamura Y: Reactive oxygen species and angiogenesis: NADPH oxidase as target for cancer therapy. Cancer Lett 266: 37-52, 2008.

37. Shono T, Yokoyama N, Uesaka T, Kuroda J, Takeya R, Yamasaki T, Amano T, Mizoguchi M, Suzuki SO, Niiro H, et al: Enhanced expression of NADPH oxidase Nox4 in human gliomas and its roles in cell proliferation and survival. Int $\mathbf{J}$ Cancer 123 : 787-792, 2008

38. Yamaura M, Mitsushita J, Furuta S, Kiniwa Y, Ashida A, Goto Y, Shang WH, Kubodera M, Kato M, Takata M, et al: NADPH oxidase 4 contributes to transformation phenotype of melanoma cells by regulating $\mathrm{G} 2-\mathrm{M}$ cell cycle progression. Cancer Res 69: 2647-2654, 2009.

39. Graham KA, Kulawiec M, Owens KM, Li X, Desouki MM, Chandra D and Singh KK: NADPH oxidase 4 is an oncoprotein localized to mitochondria. Cancer Biol Ther 10: 223-231, 2010.

40. Suzuki Y, Murakami H, Kawaguchi K, Tanigushi T, Fujii M, Shinjo K, Kondo Y, Osada H, Shimokata K, Horio Y, et al: Activation of the PI3K-AKT pathway in human malignant mesothelioma cells. Mol Med Rep 2: 181-188, 2009.

41. Cole GW Jr, Alleva AM, Zuo JT, Sehgal SS, Yeow WS, Schrump DS and Nguyen DM: Suppression of pro-metastasis phenotypes expression in malignant pleural mesothelioma by the PI3K inhibitor LY294002 or the MEK inhibitor UO126. Anticancer Res 26A: 809-821, 2006. 